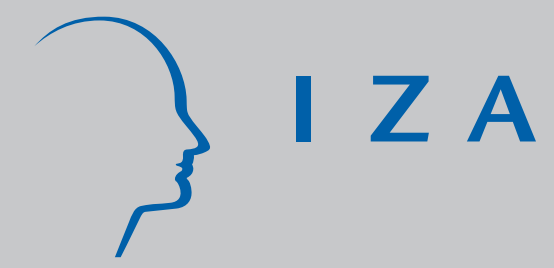

IZA DP No. 260

Temporary J obs, Employ Protection and Labor Market Performance

Pierre Cahuc

Fabien Postel-Vinay

February 2001 


\title{
Temporary Jobs, Employment Protection and Labor Market Performance
}

\author{
Pierre Cahuc \\ Université Paris 1-Eurequa, Crest, Institut Universitaire de France and IZA, Bonn \\ Fabien Postel-Vinay \\ INRA-LEA
}

Discussion Paper No. 260

February 2001

\author{
IZA \\ P.O. Box 7240 \\ D-53072 Bonn \\ Germany \\ Tel.: +49-228-3894-0 \\ Fax: +49-228-3894-210 \\ Email: iza@iza.org
}

This Discussion Paper is issued within the framework of IZA's research areas Mobility and Flexibility of Labor Markets and The Welfare State and Labor Markets. Any opinions expressed here are those of the author(s) and not those of the institute. Research disseminated by IZA may include views on policy, but the institute itself takes no institutional policy positions.

The Institute for the Study of Labor (IZA) in Bonn is a local and virtual international research center and a place of communication between science, politics and business. IZA is an independent, nonprofit limited liability company (Gesellschaft mit beschränkter Haftung) supported by the Deutsche Post AG. The center is associated with the University of Bonn and offers a stimulating research environment through its research networks, research support, and visitors and doctoral programs. IZA engages in (i) original and internationally competitive research in all fields of labor economics, (ii) development of policy concepts, and (iii) dissemination of research results and concepts to the interested public. The current research program deals with (1) mobility and flexibility of labor markets, (2) internationalization of labor markets and European integration, (3) the welfare state and labor markets, (4) labor markets in transition, (5) the future of work, (6) project evaluation and (7) general labor economics.

IZA Discussion Papers often represent preliminary work and are circulated to encourage discussion. Citation of such a paper should account for its provisional character. 
IZA Discussion Paper No. 260

February 2001

\title{
ABSTRACT \\ Temporary Jobs, Employment Protection and Labor Market Performance*
}

\begin{abstract}
Many European labor markets are characterized by heavy employment protection taxes and the widespread use of fixed-duration contracts. The simultaneous use of these two policy instruments seems somewhat contradictory since the former primarily aims at limiting job destruction whereas the latter clearly intensifies it. In this paper, we use a simple matching model with endogenous job destructions to analyze the impact of a combination of the two policies. We find that the political support of insiders to firing restrictions does not necessarily worsen unemployment. In fact, it may be the willingness of a majority of workers to support the combination of two instruments with opposite effects on job destruction and job creation that increase unemployment and deteriorates efficiency. Moreover, we argue, that the concentration of firm ownership is likely to influence labor market regulations. We show that the preferred point of a majority of workers is a very flexible labor market, without any firing cost when profits are evenly distributed across the labor force (which portrays a situation where firm ownership is extremely dispersed), whereas a combination of job protection and temporary jobs is preferred by workers when the share of profits that they earn is zero (which corresponds to a situation where firm ownership is concentrated among a few shareholders not participating in the labor market).
\end{abstract}

JEL Classification: H29, J23, J38, J41, J64

Keywords: Unemployment, fixed duration contracts, job destruction, employment protection

\author{
Pierre Cahuc \\ EUREQua, CNRS \\ Université Paris 1-Panthéon-Sorbonne \\ 106-112, Boulevard de l'hôpital \\ 75013, Paris \\ France \\ E-mail : cahuc@univ-paris1.fr
}

\footnotetext{
"Part of this research was undertaken while Fabien Postel-Vinay was visiting the Department of Economics at the University of British Columbia. We are grateful to seminar participants at UBC, CEPREMAP (Paris), IIES (Stockholm) and INRA (Paris), and particularly to Paul Beaudry, Jean-Pascal Bénassy, Patrick Fève, Torsten Persson, Gianluca Violante and Fabrizio Zilibotti.
} 


\section{Introduction}

In response to the dramatic rise in unemployment they faced since the end of the $1970 \mathrm{~s}$, many European governments made a simultaneous use of two apparently diverging policy instruments. The first one clearly pushed into the direction of a more stringent labor market regulation: It consisted of maintaining or even sometimes reinforcing a generally already strong legislation on employment protection, with the idea of slowing down job destruction. Meanwhile, the second one was a definite step toward more flexibility: It consisted of introducing the possibility of hiring workers on flexible, fixed-duration contracts, aiming at fostering job creation. At the end of the seventies, labor market regulations required that temporary jobs were destined to specific tasks, characterized by large variations in productivity, due to important seasonal variations in demand for instance. But those regulations have changed somewhat since the eighties, and it is now possible in a number of European countries to hire workers on a temporary basis even on jobs which are not subject to large variations in productivity. For instance, in Spain (Cabrales and Hopenhayn, 1997), in Germany (Rogowski and Schömann, 1996) and in France (Barthelemy and Jaulent, 1997), the use of temporary jobs is authorizes quasi unconditionally for certain groups of workers (such as youths, seniors, long-term unemployed...), and restrictions on the use of such contracts for other categories of labor have been slackened. As a result, in some of those countries, the bulk of recent hires have been on temporary jobs (about $80 \%$ in France and over $90 \%$ in Spain), even though it is hard to believe that the share of newly created jobs for which the use of a worker for a short period only is 'objectively' justified is that high. As Bentolila and Dolado (1994), Saint Paul (1996) and Cabrales and Hopenhayn (1997) emphasized, this evolution toward a more flexible labor market has been started to bring down unemployment without harming the so-called 'insiders' who are protected by high job security.

Does introducing flexibility in this particular way actually help increase employment? The literature on job security provisions does not deliver a clear-cut answer. The impact of firing costs on employment and labor market flows has been thoroughly analyzed in a number of important contributions which generally show that a more stringent employment protection has an ambiguous impact on the level of overall employment, but reduces labor flows (Bentolila and Bertola, 1990, Bertola, 1990, Bentolila and Saint-Paul, 1992, Bentolila and Dolado, 1994, Garibaldi, 1998, Hopenhayn and Rogerson, 1993, Ljungqvist, 1998, Millard and Mortensen, 1997, Mortensen and Pissarides, 1994, 1999). The role of fixed-duration contracts also seems to be unclear. It is generally concluded that the introduction of fixed-duration contracts is equivalent to a reduction in firing 
cost and that its impact on unemployment is therefore ambiguous (Bentolila and Saint-Paul, 1992, Bentolila and Dolado, 1994, Saint-Paul, 1996, Cabrales and Hopenhayn, 1997, Aguirregabiria and Alonso-Borrego, 1999, Boeri, 1999, Wasmer, 1999, Garibaldi and Violante, 1999, Blanchard and Landier, 2000, Goux and Maurin, 2000).

In this paper, we focus on two common features shared by many European labor markets: $1^{\circ}$ ) firms can create both permanent and temporary jobs and $2^{\circ}$ ) firms convert a certain share of the latter to permanent contract at their expiration (the rest being terminated at no cost). Our paper explicitly analyzes the consequences of this specific combination of temporary and permanent jobs. This is, as far as we are aware, a novelty, as it is generally assumed either that firms can create both permanent and temporary jobs, the latter being necessarily destroyed when they expire (Bentolila and Saint-Paul, 1994, Bentolila and Dolado, 1994, Saint-Paul, 1996, Wasmer, 1999), or that firms only create "entry-level" jobs, which can be either converted or destroyed after a given time period (Garibaldi and Violante, 1999, Goux and Maurin, 2000, Blanchard and Landier, 2000). Our approach allows for a precise analysis of job creation and destruction when a distinction between temporary and permanent jobs exists through labor market legislation, a situation often met in Europe.

Our concern is the consequences of employment protection regulations on unemployment, welfare and income distribution. We thus need to embed the above enumerated two features into an equilibrium model of the labor market. As will appear in the paper, the Mortensen and Pissarides (1994) matching model with endogenous job destruction is a good candidate. In this framework, we find that a more flexible regulation on fixed-term contracts may actually destroy jobs, increase unemployment, and reduce aggregate welfare, especially when firing costs are high. Facilitating the creation of more temporary jobs fosters job creation but also triggers an increase in job destruction, the latter effect having a larger impact on unemployment when firing costs are large. The intuition for this result becomes clear if one realizes that firms transform temporary jobs into permanent jobs. For instance, in France, between 1987 and 1991, approximately one third of short-term employment contracts were converted to long-term contracts at their expiration (Abowd, Corbel and Kramarz, 1995), which implied a share of temporary jobs in total employment of around $15 \%$ in this period. Obviously, the higher the firing costs, the lower the share of temporary jobs transformed into permanent jobs, because large firing costs are an incentive for employers to use temporary jobs in sequence rather than converting them to long-term contracts, which are subject to the firing costs. Consequently, a policy that permits the opening of more temporary jobs fosters both 
job creation and destruction, the latter effect being strengthened when firing costs are large. This implies that the spread of temporary jobs is more likely to raise unemployment when it comes on a labor market already regulated by stringent permanent job security provisions ${ }^{1}$.

In fact, theory predicts that allowing for more temporary jobs to be created while imposing positive firing costs fosters both job creation and job destruction, with a consequently ambiguous overall impact on equilibrium unemployment. But simulations of a calibrated version of our model for a typical European labor market nonetheless suggest that the effect on job destruction is stronger, resulting in a higher unemployment rate for economies with both stringent firing restrictions and a widespread use of fixed-duration contracts. Finally, simulations show that the net present value of future aggregate net production flows-which is a consistent measure of aggregate welfare when individuals are assumed to be risk-neutral - is typically reduced by the combined use of firing restrictions and fixed-term contracts.

Given those preliminary results, the main question we want to address in this paper is that of the causes that led some European governments to use those inefficient combinations of temporary jobs and stringent dismissal restrictions. An answer to this question, which also is the main result of this paper, is given by a further welfare and income distribution analysis ${ }^{2}$. Our benchmark case is a situation where profits are not redistributed to workers. In that case, the above mentioned simulations show that a measure that facilitates the creation of temporary jobs, which raises the unemployment exit rate, improves the welfare of every worker whose status (unemployed, employed either on a permanent or on a temporary job) does not change as a direct result of that measure. Accordingly, only those workers whose jobs are directly threatened by the change of policy can bear losses when temporary jobs are made easier to create. Moreover, it appears that workers employed on long term jobs prefer higher firing costs than unemployed workers and workers on temporary jobs. Overall, both the aggregate discounted income of workers and the welfare of employees with permanent jobs reach a maximum in a situation in which firms are allowed to create as many temporary jobs as they want and have to pay firing costs that amounts to about 3 months of the average production of a worker. As a consequence, in the world that we describe in our benchmark case, starting from a laissez-faire situation without employment protection or temporary jobs, a small simultaneous increase in the share of temporary jobs and firing costs is always supported by

\footnotetext{
${ }^{1}$ This result concurs with Blanchard's and Landier's (2000) conclusions, which were obtained independently in a somewhat similar framework.

${ }^{2}$ The absence of risk-aversion from the economy that we describe authorizes us to speak of welfare when we really look at present discounted income. This somewhat restrictive definition should be kept in mind.
} 
a vast majority of workers, even though it is inefficient. Our analysis thus suggests that unemployment and labor market inefficiency do not originate from the sole political support of insiders to employment protection, but could rather be the result of a consensus among a very large majority of workers in favor of a "dual" labor market.

Surprisingly, it is found that temporary jobs diminish aggregate profits. Indeed, loosening the restrictions imposed on the creation of temporary jobs has two counteracting effects on profits: On one hand it facilitates the creation of more profitable jobs, but on the other, by increasing the job finding rate, it also increases wage pressure, which is detrimental to profits. We find that the second effect dominates for a wide range of parameter values, and that aggregate profits are (slightly) decreased in equilibrium when firms are allowed to create more temporary jobs. Obviously, firing costs are also bad for profits and, overall, aggregate profits are lower when there is a combination of temporary jobs and firing costs.

Those results suggest that the distribution of firm ownership is likely to influence labor market regulations. The share of profits earned by workers was zero in our benchmark case, which would be the case in an economy where equity ownership is concentrated among a few shareholders who do not participate in the labor market. The opposite case of extreme dispersion in firm ownership is a situation where profits are evenly distributed to all workers. We show in this last case that the preferred point of workers is a very flexible labor market, with virtually no restriction on dismissals. This contrast between the two exercises is consistent with the stylized view that corporate ownership is more dispersed in Anglo-Saxon economies than in continental Europe (see e.g. La Porta, LopezDe-Silanes and Shleifer, 1999), since another stylized view (which will be documented later in the paper), is that Anglo-Saxon labor markets are less regulated and more flexible than in continental Europe.

The paper is organized as follows: The next section briefly documents the importance of fixedduration jobs and firing costs in some European economies. Section 3 exposes the theoretical framework we use to address the question at hand, and characterizes its steady-state. Section 4 studies both qualitatively and quantitatively the effects of labor market policy-i.e. the combined use of firing restrictions and fixed-duration contracts - on the values of some variables of interest. Section 5 concludes. 


\section{Some facts about labor market regulation}

Several contributions (e.g. Bertola, 1990, Grubb and Wells, 1993, OECD, 1994) have constructed synthetic indicators of the 'strictness' of employment protection in most OECD countries. Elaborating on those contributions, OECD (1999, chapter 2) provides a ranking of 27 countries by order of strictness of their employment protection legislation. Table 1 reports this ranking for European (both EU and EFTA) and North American countries by the end of the 1990s.

Table 1: Strictness of employment protection regulations for regular employment by the end of the 90's (source: OECD, 1999)

\begin{tabular}{lc|lc}
\hline \hline \multicolumn{1}{c|}{ Country } & Indicator $^{\mathrm{a}}$ & Country & Indicator \\
\hline USA & .2 (least strict) & Norway & 2.4 \\
UK & .8 & Greece & 2.4 \\
Canada & .9 & Austria & 2.6 \\
Switzerland & 1.2 & Spain & 2.6 \\
Belgium & 1.5 & Germany & 2.8 \\
Denmark & 1.6 & Sweden & 2.8 \\
Ireland & 1.6 & Italy & 2.8 \\
Finland & 2.1 & Netherlands & 3.1 \\
France & 2.3 & Portugal & 4.3 (strictest) \\
\hline \hline
\end{tabular}

${ }^{\mathrm{a}}$ The indicator takes values from 0 to 6 . Its value increases with the global

strictness of employment protection regulations.

The same chapter of OECD (1999) also provides a synthetic account of the regulation on fixedduration contracts in European economies (see table 2). Even if restrictive conditions apply to the number of possible renewals of such contracts, it appears that, in most countries, access to fixedduration contracts is made relatively easy. Except for Greece, where fixed-duration contracts are authorized only for temporary jobs, either there are no restrictions at all on the use of such contracts, or 'specific conditions' apply. 'Specific conditions' means that the specific needs and situation of the employer and/or the employee are taken into account in applications for fixed-duration contracts and that special derogations to the normally applicable rules may be granted.

Table 3 reports the share of temporary jobs in total employment in European economies. One sees from table 3 that, even though fixed-duration contracts constitute the bulk of employment inflows, they hardly account for over $10 \%$ of total employment (Spain being a notable exception). The reason for this is obviously that fixed-duration contracts are temporary by nature, so their lifetime is much shorter than those of regular, long-term contracts.

A last feature of interest regarding fixed-duration contracts is the extent to which they can be transformed into regular, permanent jobs. One sees that in some countries there are restrictions 
Table 2: Regulation on fixed-duration contracts (source: OECD, 1999)

\begin{tabular}{lcccc}
\hline \hline Country & $\begin{array}{c}\text { Job } \\
\text { requisites }\end{array}$ & $\begin{array}{c}\text { Max. number } \\
\text { of renewals }\end{array}$ & $\begin{array}{c}\text { Max. cumulated } \\
\text { length (months) }\end{array}$ & $\begin{array}{c}\text { Global } \\
\text { strictness }\end{array}$ \\
\hline EU & Specific conditions & 3 & 30 & 2.8 \\
Belgium & None & .5 & Unlimited & .9 \\
Denmark & Specific conditions & 1 & 18 & 3.6 \\
France & Specific conditions & 3 & 24 & 2.3 \\
Germany & Temporary jobs only & 1.5 & Unlimited & 4.8 \\
Greece & None & Unlimited & Unlimited & .3 \\
Ireland & Specific conditions & 1 & 15 & 3.8 \\
Italy & None & 2 & Unlimited & 1.2 \\
Netherlands & Specific conditions & 2 & 30 & 3.0 \\
Portugal & Specific conditions & 5 & 36 & 3.5 \\
Spain & None & Unlimited & Unlimited & .3 \\
UK & & & & \\
\hline EFTA & None & 0.5 & Unlimited & 1.8 \\
Austria & Specific conditions & 0.5 & Unlimited & 1.9 \\
Finland & Specific conditions & 0.5 & Unlimited & 2.8 \\
Norway & None & Unlimited & 12 & 1.6 \\
Sweden & None & .5 & Unlimited & .9 \\
Switzerland & & & & \\
\hline \hline a The indicator takes values from 0 to 6. Its value increases with the global strictness of regulations on & \\
temporary employment. & & &
\end{tabular}

Table 3: Share of temporary jobs in total employment (source: OECD, 1996)

\begin{tabular}{ll|ll}
\hline \hline \multicolumn{1}{c}{ Country } & Share (\%) & Country & Share(\%) \\
\hline Belgium & 5.1 & Germany & 10.5 \\
UK & 5.4 & France & 11 \\
Italy & 7.5 & Portugal & 11 \\
Ireland & 9 & Denmark & 11.5 \\
Netherlands & 10 & Finland & 13 \\
Greece & 10.5 & Spain & 33 \\
\hline \hline
\end{tabular}


on the length of fixed-duration contracts, through the introduction of a maximal cumulated length and/or a maximal number of renewals. Accordingly, in such countries, employers must choose between terminating a fixed-duration contract or converting the contract to a permanent one. It is worth noting that this trade-off can also exist in countries where there is no explicit restriction on the length of fixed duration contracts. For instance, in the UK, the Employment Protection Consolidation Act (1978) states that the end of a fixed term contract may be considered as an unfair dismissal giving rise to an award and/or a reinstatement (see Addison and Siebert, 1993). In this case, the difference between a temporary and a permanent job is quite subtle, and depends on the decision of the tribunal. A way to introduce the possibility to use temporary jobs with certainty is to impose a qualifying period before a claim of unfair dismissal or redundancy payment can be brought to the Industrial Tribunal. At the end of this qualifying period, which had been raised from six months to one year in 1979 and to two years in 1980, the employers face the same trade-off between terminating or transforming the temporary jobs as in countries where there are explicit restrictions.

Overall, there are many ways to regulate the use of temporary jobs, but European labor market regulations have evolved toward more flexibility, by facilitating the creation of temporary jobs. The conditions under which such jobs may be opened are related to the characteristics of both workers and jobs, and they are often loosely defined, as they depend to a large extent on the degree of regulation enforcement. As shown by Figure 1, a consequence of this situation is that there is a larger share of temporary jobs in countries with more stringent job protection. Accordingly, this Figure suggests that temporary jobs are actually used to re-introduce some flexibility when firing costs are high.

The following sections try to assess the impact on labor market performance and welfare of this form of flexibility.

\section{The basic theoretical setup}

\subsection{Preliminary assumptions}

The basic environment borrows from a discrete time version of a model close to Mortensen and Pissarides (1994). An endogenously sized continuum of competitive firms produce a numéraire output, using labor as sole input. Each firm is endowed with a fixed-coefficients technology, requiring one worker to produce $\varepsilon$ units of output in period $t$. As in Mortensen and Pissarides (1994), $\varepsilon$ is a random, job-specific productivity parameter selected from a distribution $\phi=\Phi^{\prime}$ over some interval 


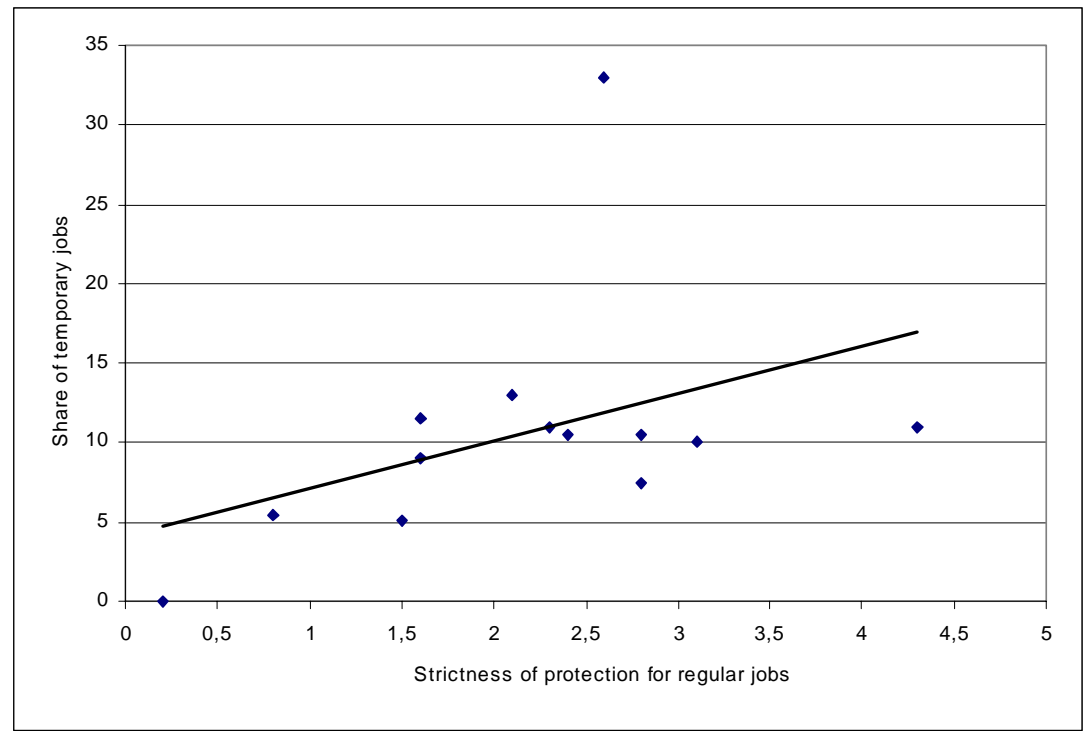

Figure 1: The relation between the share of temporary jobs and the strictness of protection for regular jobs. Source: OECD.

$[\underline{\varepsilon}, \bar{\varepsilon}]$. Every new job starts off with productivity $\varepsilon$ drawn from the distribution $\phi$. Every continuing job has a constant per period probability $\lambda \in[0,1]$ of being hit by a productivity shock, which consists in drawing a new value for the productivity from the distribution $\phi$.

Hiring a worker and searching for a job are costly activities. Vacant jobs and unemployed workers - the only job seekers, by assumption - are brought together in pairs through an imperfect matching process. This process is captured by the customary matching function, which relates per period total contacts to the number of seekers on each side of the market. If $u_{t}\left(v_{t}\right)$ is the period $t$ rate of unemployment (job vacancy), and if total labor force participation is normalized to 1 in every period $t$, the number of employer-worker contacts in period $t$ is given by $m\left(u_{t}, v_{t}\right)$, where the matching function is twice continuously differentiable, increasing and concave in both of its arguments, and linearly homogeneous ${ }^{3}$. Linear homogeneity of the matching function allows to express the per period probability for a vacant job (unemployed worker) to meet an unemployed worker (a vacant job) as a function of the labor market tightness ratio, $\theta_{t}=v_{t} / u_{t}$. A vacant job can meet on average $m\left(u_{t}, v_{t}\right) / v_{t}=q\left(\theta_{t}\right)$ unemployed workers per period, with $q^{\prime}(\cdot)<0$. Similarly, the rate at which unemployed job seekers can meet jobs is $\theta_{t} q\left(\theta_{t}\right)$, an increasing function of $\theta_{t}$. It is worth noting that not all job contacts will lead to job creation because some job matches turn out not to be productive enough. Indeed, the starting value of productivity $\varepsilon$ is revealed to both

\footnotetext{
${ }^{3}$ At least over the domain $\{(x, y) \mid m(x, y) \leq \min (x, y)\}$, to which we shall confine the analysis.
} 
the worker and the would-be employer of any new match right after the match is formed, and it may turn out to be too low to compensate either party for their search efforts. More specifically, we will show that there exist reservation productivity levels below which neither the worker nor the employer who have just met want to trade.

We depart from the basic Mortensen-Pissarides economy by assuming that two types of labor contracts coexist: Long-term contracts and fixed-duration (or short-term) contracts. Long-term contracts are the 'regular' type of contracts. They do not mention any pre-determined duration, and can be terminated in any period at a fixed cost $f$, incurred by the firm. The cost $f$ will be referred to as the firing cost in the remainder and is thought of as a measure of job security. It is an exogenous policy tool. Note that it is a fixed cost, not a transfer from the firm to the worker (such as severance pay), but a transfer from the firm to the government that is evenly redistributed to the whole population through lump-sum transfers. Moreover, we deem it realistic to assume that only continuing matches (i.e. matches at least one period old) are subject to firing costs.

Fixed duration contracts are one-period contracts. After one period, they can either be terminated at no cost, or converted into a long-term contract. These features are meant to capture the main characteristics of the 'flexible', fixed-duration contracts that have been introduced in many European economies since the beginning of the 80 s (see the introductory discussion of this paper). Under those assumptions, the only difference between a short- and a long-term contract is that the former is exempt from the firing cost for one period. Therefore, if both types of contracts imply equal hiring costs, what we shall assume, short-term contracts are always preferred by firms - and, under the assumption of efficient surplus sharing, by workers as well. However, we put a restriction on the creation of short-term jobs through the assumption that any short-term contract must be approved by the government, otherwise it is automatically transformed into a long-term contract. Approval is granted to an exogenous fraction $p$ of the new matches in each period, where $p$ is taken as another policy instrument. It is assumed that the type of contract that can be offered is not known by the employer before he meets a worker in order to capture two important facts. First, the right to use a fixed-duration contract generally depends on worker characteristics which are not known before the match is formed. Second, in many countries, the spread of fixed-duration contracts occurred mainly because of a rather loose enforcement of the existing regulations (again, see the introductory discussion). Accordingly, an employer who offers a temporary job faces a risk of seeing it converted into a permanent one. 


\subsection{Wage formation, job creation and job destruction}

The decisions of opening a new vacant job slot or terminating a job of either type are based on the asset values of the various options. To derive those values, we need to introduce a bit of notation. First, a job can be in either one of the following four states: Vacant (state $v$ ), operating under a short-term contract (state $s$ ), in its first period of operation under a long-term contract and thus exempt from the firing restrictions (state 0), operating under a long-term contract for more than one period and thus subject to the firing restrictions (state $l$ ). To each of these states corresponds a distinct asset value, which we now define. All values below are steady-state.

- $\Pi^{v}$ : value to the firm of a vacant job slot;

- $\Pi^{s}(\varepsilon)$ : value to the firm of a short-term job with productivity parameter $\varepsilon$;

- $\Pi^{0}(\varepsilon)$ : value to the firm of a new long-term job with productivity parameter $\varepsilon$;

- $\Pi^{l}(\varepsilon)$ : value to the firm of a continuing long-term job with productivity parameter $\varepsilon$;

- $V^{s}(\varepsilon)$ : value to the worker of a short-term job with productivity parameter $\varepsilon$;

- $V^{\mathbf{0}}(\varepsilon)$ : value to the worker of a new long-term job with productivity parameter $\varepsilon$;

- $V^{l}(\varepsilon)$ : value to the worker of a continuing long-term job with productivity parameter $\varepsilon$;

- $V^{u}$ : value to the worker of unemployment.

For any type of job, we finally define the joint surplus associated with the job as the sum of its values to the firm and the worker net of their respective values of continued search. Short-term contracts or recent long-term contracts-i.e. jobs of type 0 and $s$-are exempt of firing costs. Thus, the value to the firm of breaking the contract is simply the value of a vacant job, $\Pi^{v}$ and the corresponding surpluses are respectively

$$
S^{0}(\varepsilon)=\left[\Pi^{0}(\varepsilon)-\Pi^{v}\right]+\left[V^{0}(\varepsilon)-V^{u}\right] \quad \text { and } \quad S^{s}(\varepsilon)=\left[\Pi^{s}(\varepsilon)-\Pi^{v}\right]+\left[V^{s}(\varepsilon)-V^{u}\right] .
$$

In turn, the firm incurs the firing cost $f$ upon terminating a continuing long-term job (type $l$ ), which makes the value of breaking a contract of type $l$ equal to $\Pi^{v}-f$. The surplus from a continuing long-term job is therefore given by $S^{l}(\varepsilon)=\left[\Pi^{l}(\varepsilon)-\Pi^{v}+f\right]+\left[V^{l}(\varepsilon)-V^{u}\right]$.

Wages are the outcome of a bilateral bargain between each firm and its employee. The bargain is revised at the beginning of each period once productivity shocks have occurred. Denoting the 
relative 'bargaining power' of the worker by $\gamma \in[0,1]$, this type of continuously revised bargain sets a wage so as to split the surplus in fixed proportions at all dates, so that:

$$
\Pi^{i}(\varepsilon)-\Pi^{v}=(1-\gamma) S^{i}(\varepsilon) \text { for } i=0, s, \text { and } \Pi^{l}(\varepsilon)-\left(\Pi^{v}-f\right)=(1-\gamma) S^{l}(\varepsilon)
$$

It is thus assumed that workers on fixed-duration jobs have the same 'bargaining power' as workers on long-term jobs. This is consistent with the regulation on fixed-duration contracts in most European countries ${ }^{4}$. But, obviously, the employer has to pay a firing cost only if he terminates a permanent job, which implies that he gets $\Pi^{v}$ if he destroys a temporary job and $\left(\Pi^{v}-f\right)$ if the job is a permanent one.

Keeping a vacant job open implies a per period fixed cost of $h$, and returns a contact with probability $q(\theta)$ in each period. When there is a contact, the employer-worker pair discovers the starting match-specific productivity $\varepsilon$, and the type of job, either short-term or long-term, that they may create. Recall that $\varepsilon$ is drawn from the distribution $\phi$ and that a short-term job can be created with probability $p$. A new match with productivity $\varepsilon$ has an asset value of $\Pi^{s}(\varepsilon)$ if it leads to a short-term job, $\Pi^{v}$. The employer decides to hire the worker if $\Pi^{s}(\varepsilon)$ is larger than the asset value of a vacant job. If the job is long-term, it is worth $\Pi^{0}(\varepsilon)$ and the worker is hired only if $\Pi^{0}(\varepsilon)>\Pi^{v}$. The future is discounted at a fixed rate $(1-\beta) / \beta, \beta<1$. The value of a vacant job thus solves:

$$
\begin{aligned}
\Pi^{v}=-h+\beta q(\theta)\left[p \int_{\underline{\varepsilon}}^{\bar{\varepsilon}} \operatorname{Max}\left[\Pi^{s}(x), \Pi^{v}\right] d \Phi(x)+\right. & \\
& \left.(1-p) \int_{\underline{\varepsilon}}^{\bar{\varepsilon}} \operatorname{Max}\left[\Pi^{0}(x), \Pi^{v}\right] d \Phi(x)\right]+\beta[1-q(\theta)] \Pi^{v} .
\end{aligned}
$$

An unemployed worker is assumed to enjoy the flow earning $z$ that includes leisure, unemployment benefits, home production, etc. The lump sum transfer used to redistribute the proceeds of the employment protection tax is denoted by $\sigma$. The rate at which the unemployed worker comes in contact with a vacant job slot is $\theta q(\theta)$. Once contact is made, the productivity of the (potential) job is drawn from the distribution $\phi$, and the chance of this job being approved as a fixed-duration contract is $p$. If workers are risk-neutral and have the same discount factor as entrepreneurs, then

\footnotetext{
${ }^{4}$ For instance, in France, a worker hired on a fixed-duration contract explicitly "benefits from the same rights, including trade union rights, as any other employee in the firm". More information on this type of labor contract can be found in the French Ministry of Labor's web page: http://www.travail.gouv.fr .
} 
the value of unemployment solves:

$$
\begin{aligned}
V^{u}=z+\sigma+\beta \theta q(\theta)\left[p \int_{\underline{\varepsilon}}^{\bar{\varepsilon}} \operatorname{Max}\left[V^{s}(x), V^{u}\right] d \Phi(x)+\right. \\
\left.(1-p) \int_{\underline{\varepsilon}}^{\bar{\varepsilon}} \operatorname{Max}\left[V^{0}(x), V^{u}\right] d \Phi(x)\right]+\beta[1-\theta q(\theta)] V^{u} .
\end{aligned}
$$

A short-term job lasts for only one period and pays a wage $w_{s}(\varepsilon)$. At the end of the period, it may be hit by a productivity shock with probability $\lambda$. The firm and the worker then observe the new value of $\varepsilon$ for that job and decide whether to perpetuate it as a permanent job and share its net worth $S^{0}(\varepsilon)$, or to destroy it at no cost and go back to the search market. The values to the firm and to the worker of a short-term job thus solve the following two equations:

$$
\begin{gathered}
\Pi^{s}(\varepsilon)=\varepsilon-w_{s}(\varepsilon)+\beta\left\{(1-\lambda) \operatorname{Max}\left[\Pi^{0}(\varepsilon), \Pi^{v}\right]+\lambda \int_{\underline{\varepsilon}}^{\bar{\varepsilon}} \operatorname{Max}\left[\Pi^{0}(x), \Pi^{v}\right] d \Phi(x)\right\}, \\
V^{s}(\varepsilon)=w_{s}(\varepsilon)+\sigma+\beta\left\{(1-\lambda) \operatorname{Max}\left[V^{0}(\varepsilon), V^{u}\right]+\lambda \int_{\underline{\varepsilon}}^{\bar{\varepsilon}} \operatorname{Max}\left[V^{0}(x), V^{u}\right] d \Phi(x)\right\} .
\end{gathered}
$$

A new long-term job with productivity $\varepsilon$ pays a wage $w_{0}(\varepsilon)$. At the end of the period, having observed their new value of $\varepsilon$, the firm and the workers are left over with basically the same options as with short-term jobs: Either they stay together in a (continuing) long-term contract, or they dissolve the match. The difference here is that dissolving the match will cost the firm the firing cost f. Accordingly, the values of a new long-term job solve:

$$
\begin{gathered}
\Pi^{0}(\varepsilon)=\varepsilon-w_{0}(\varepsilon)+\beta\left\{(1-\lambda) \operatorname{Max}\left[\Pi^{l}(\varepsilon), \Pi^{v}-f\right]+\lambda \int_{\underline{\varepsilon}}^{\bar{\varepsilon}} \operatorname{Max}\left[\Pi^{l}(x), \Pi^{v}-f\right] d \Phi(x)\right\}, \\
V^{\mathbf{0}}(\varepsilon)=w_{\mathbf{0}}(\varepsilon)+\sigma+\beta\left\{(1-\lambda) \operatorname{Max}\left[V^{l}(\varepsilon), V^{u}\right]+\lambda \int_{\underline{\varepsilon}}^{\bar{\varepsilon}} \operatorname{Max}\left[V^{l}(x), V^{u}\right] d \Phi(x)\right\} .
\end{gathered}
$$

The only values that are left to write down are those of a continuing long-term contract, $\Pi^{l}(\varepsilon)$ and $V^{l}(\varepsilon)$. The only difference between a new and a continuing long-term job is that, in the latter, the worker can use the firing cost incurred by the firm as an additional threat in the wage bargaining (see above eqn. (1)). Therefore, for a given $\varepsilon$, the wage $w_{l}(\varepsilon)$ prevailing in a job of type $l$ will be larger than that in a job of type 0 . Apart from that, the Bellman equations characterizing $\Pi^{l}(\varepsilon)$ and $V^{l}(\varepsilon)$ look exactly like $(6)$ and $(7)$ :

$$
\Pi^{l}(\varepsilon)=\varepsilon-w_{l}(\varepsilon)+\beta\left\{(1-\lambda) \operatorname{Max}\left[\Pi^{l}(\varepsilon), \Pi^{v}-f\right]+\lambda \int_{\underline{\varepsilon}}^{\bar{\varepsilon}} \operatorname{Max}\left[\Pi^{l}(x), \Pi^{v}-f\right] d \Phi(x)\right\},
$$




$$
V^{l}(\varepsilon)=w_{l}(\varepsilon)+\sigma+\beta\left\{(1-\lambda) \operatorname{Max}\left[V^{l}(\varepsilon), V^{u}\right]+\lambda \int_{\underline{\varepsilon}}^{\bar{\varepsilon}} \operatorname{Max}\left[V^{l}(x), V^{u}\right] d \Phi(x)\right\} .
$$

Job creation is governed by the assumption of free entry onto the search market. Free entry drives the value of a vacant job slot $\Pi^{v}$ to zero in each period. From (2) and the surplus sharing rule (1), this implies the following equality in each period:

$$
\frac{h}{\beta(1-\gamma) q(\theta)}=p \int_{\underline{\varepsilon}}^{\bar{\varepsilon}} \operatorname{Max}\left[S^{s}(x), 0\right] d \Phi(x)+(1-p) \int_{\underline{\varepsilon}}^{\bar{\varepsilon}} \operatorname{Max}\left[S^{0}(x), 0\right] d \Phi(x) .
$$

Using this relationship together with (1) to substitute into equations (3) to (7), one can derive the expressions of the total match surpluses as follows:

$$
\begin{gathered}
S^{s}(\varepsilon)=\varepsilon-z+\beta\left\{(1-\lambda) \operatorname{Max}\left[S^{\mathbf{0}}(\varepsilon), 0\right]+\lambda \int_{\underline{\varepsilon}}^{\bar{\varepsilon}} \operatorname{Max}\left[S^{\mathbf{0}}(x), 0\right] d \Phi(x)\right\}-\frac{\gamma}{1-\gamma} h \theta, \\
S^{\mathbf{0}}(\varepsilon)=\varepsilon-z+\beta\left\{(1-\lambda) \operatorname{Max}\left[S^{l}(\varepsilon), 0\right]+\lambda \int_{\underline{\varepsilon}}^{\bar{\varepsilon}} \operatorname{Max}\left[S^{l}(x), 0\right] d \Phi(x)-f\right\}-\frac{\gamma}{1-\gamma} h \theta,
\end{gathered}
$$

The surplus from a continuing long-term job is simply:

$$
S^{l}(\varepsilon)=S^{0}(\varepsilon)+f
$$

The surplus from a new job is lower than from a continuing job because the employer has to pay the firing cost only once the worker has been hired. At the time of the first encounter between the worker and the employer, a disagreement cannot give rise to firing costs, because no contract is yet signed. But as soon as the worker is hired, the employer faces firing costs if he decides to terminate the job. Therefore, the loss in case of destruction of a continuing long-term job is larger than in case of a disagreement at the time of the match, which makes the surplus from continuing a job greater than the surplus from a new match.

Jobs are created or perpetuated when the surplus they generate is positive for the current productivity parameter. Since the definitions of the surpluses (11), (12) and (13) imply that each type of surplus increases with respect to the current productivity parameter, each type of job is destroyed when its productivity falls below a critical value such that its surplus becomes equal to zero. Accordingly, new matches that give rise to a short-term job are immediately destroyed before producing anything - if their productivity is lower than $\varepsilon_{s}$, where $\varepsilon_{s}$ is given by $S^{s}\left(\varepsilon_{s}\right)=0$. Similarly, the threshold value for the creation of new long-term jobs, coming either from new matches or from the transformation of short-term jobs, denoted by $\varepsilon_{0}$, is defined by $S^{0}\left(\varepsilon_{0}\right)=0$, and the threshold value for continuing long-term jobs, denoted by $\varepsilon_{l}$, is such that $S^{l}\left(\varepsilon_{l}\right)=0$. 
Therefore, from (12) and (13), the destruction rule of long-term jobs writes down as:

$$
\varepsilon_{l}-z+(1-\beta) f+\lambda \beta \int_{\varepsilon_{l}}^{\bar{\varepsilon}} S^{l}(x) d \Phi(x)-\frac{\gamma}{1-\gamma} h \theta=0 .
$$

Integration by parts of the integral term, recalling that $S^{l}\left(\varepsilon_{l}\right)=0$ and noting from (12) that $S^{\prime \prime}(\varepsilon)=1 /[1-\beta(1-\lambda)]$, changes the latter equation into:

$$
\varepsilon_{l}-z+(1-\beta) f+\frac{\lambda \beta}{1-\beta(1-\lambda)} \int_{\varepsilon_{l}}^{\bar{\varepsilon}}[1-\Phi(x)] d x=\frac{\gamma}{1-\gamma} h \theta .
$$

This equation will be referred to as the Long-Term Job Destruction rule. It makes the threshold productivity $\varepsilon_{l}$ an increasing function of the labor market tightness parameter $\theta$. The intuition behind this upward slope is that a tighter labor market yields better employment opportunities for the unemployed workers, hence pushing the value of unemployment $V^{u}$ upward. This tends to reduce the surplus, thus making the firm and its employee more exacting on how productive their match must be to compensate them for their outside options. Also note that, for a given $\theta$, higher firing costs reduce $\varepsilon_{l}$, thus tending to keep less productive jobs from being terminated. This is of course consistent with the very purpose of firing restrictions, which is to reduce the propensity to destroy jobs.

Substituting the condition $S^{\mathbf{0}}\left(\varepsilon_{\mathbf{0}}\right)=0$ into (12) yields a job acceptance rule for long-term contracts, coming either from new matches or from short-term jobs ${ }^{5}$, similar to (LTJD). A characterization of the Long-Term Job Acceptance rule can be obtained as a mixture of those two equations:

$$
\varepsilon_{0}=\varepsilon_{l}+f[1-\beta(1-\lambda)]
$$

What this equation basically says is that short-term jobs will be destroyed more often than continuing long-term jobs, because they are exempt from firing costs. In the absence of any firing costs $(f=0)$, the distinction between short- and long-term jobs is simply irrelevant, and clearly both types of jobs are destroyed on the same basis: $\varepsilon_{l}=\varepsilon_{0}$. Positive firing costs, however, reduce the option value of terminating the match, which makes it profitable to maintain less productive jobs.

New matches give rise short-term jobs only if the productivity is larger than the threshold value $\varepsilon_{s}$, such that $S^{s}\left(\varepsilon_{s}\right)=0$. Using the same 'integration by parts' trick as for (LTJD), equations (11), (LTJD) and (LTJA) allow us to define the Short-Term Job Acceptance value of productivity as:

\footnotetext{
${ }^{5}$ Obviously, the long-term job acceptance threshold $\varepsilon_{0}$ is also the short-term job destruction threshold, since a short-term job is perpetuated as a permanent one if and only if its productivity is no less than $\varepsilon_{0}$.
} 


$$
\varepsilon_{s}=\varepsilon_{l}+(1-\beta) f+\frac{\beta \lambda}{1-\beta(1-\lambda)} \int_{\varepsilon_{l}}^{\varepsilon_{0}}[1-\Phi(x)] d x .
$$

This equation states that the short-term job acceptance value of productivity is bigger than the long-term job destruction threshold value. It can also be shown that the acceptance value is lower for short-term than for long-term jobs, i.e. $\varepsilon_{\mathbf{0}} \leq \varepsilon_{s}$. Finally, the ranking of the cutoff productivities is $\varepsilon_{l} \leq \varepsilon_{s} \leq \varepsilon_{0}$.

The job creation rule is obtained by substituting (11) and (12) into the free entry condition (10). We get, after integration by parts in the two integrals: ${ }^{6}$

$$
\frac{h[1-\beta(1-\lambda)]}{\beta(1-\gamma) \cdot q(\theta)}=\int_{\varepsilon_{0}}^{\bar{\varepsilon}}[1-\Phi(x)] d x+p \cdot[1-\beta(1-\lambda)] \cdot \int_{\varepsilon_{s}}^{\varepsilon_{0}}[1-\Phi(x)] d x
$$

It is easy to check that (JC) together with (LTJA) and (STJA) makes labor market tightness a decreasing function of the reservation productivity $\varepsilon_{l}$. This simply reflects the fact that, the lower the destruction threshold $\varepsilon_{l}$, the longer the jobs last on average which raises their initial expected present value. In turn, the jobs being more profitable, firms post vacancies in greater number. Conversely, note that, for a given value of $\varepsilon_{l}$, higher firing costs reduce the expected present value of jobs, thus having an adverse effect on job creation. The overall effect of stronger employment protection thus turns out to be ambiguous a priori, since heavier firing restrictions slow down both job creation and job destruction.

Substituting the value for $\varepsilon_{s}$ and $\varepsilon_{0}$ defined in (LTJA) and (STJA) into the job creation rule (JC), and using the long-term job destruction rule (LTJD), we end up with two schedules of opposite slopes in the $\left(\varepsilon_{l}, \theta\right)$ space (see figure 2 ), that characterize the steady-state equilibrium values $\theta^{*}$ and $\varepsilon_{l}^{*}$-and hence of $\varepsilon_{\mathbf{0}}^{*}, \varepsilon_{s}^{*}$, directly from (LTJA), (STJA) respectively - see figure 2 .

\subsection{Unemployment}

The steady-state equilibrium value of the unemployment rate is readily derived with knowledge of $\theta^{*}, \varepsilon_{l}^{*}, \varepsilon_{0}^{*}$ and $\varepsilon_{s}^{*}$ and the equality of the flows into and out of the unemployment pool. In each period $t$, the number of job contacts is $m(u, v)$-recall that total labor force participation is

\footnotetext{
${ }^{6}$ Note from the definition of $S^{s}(\varepsilon)$ that its derivative w.r.t. $\varepsilon$ is defined by:
}

$$
S^{s^{\prime}}(\varepsilon)=\left\{\begin{array}{ll}
1 & \text { if } \varepsilon_{s} \leq \varepsilon<\varepsilon_{0} \\
1 /[1-\beta(1-\lambda)] & \text { if } \varepsilon \geq \varepsilon_{0}
\end{array} .\right.
$$




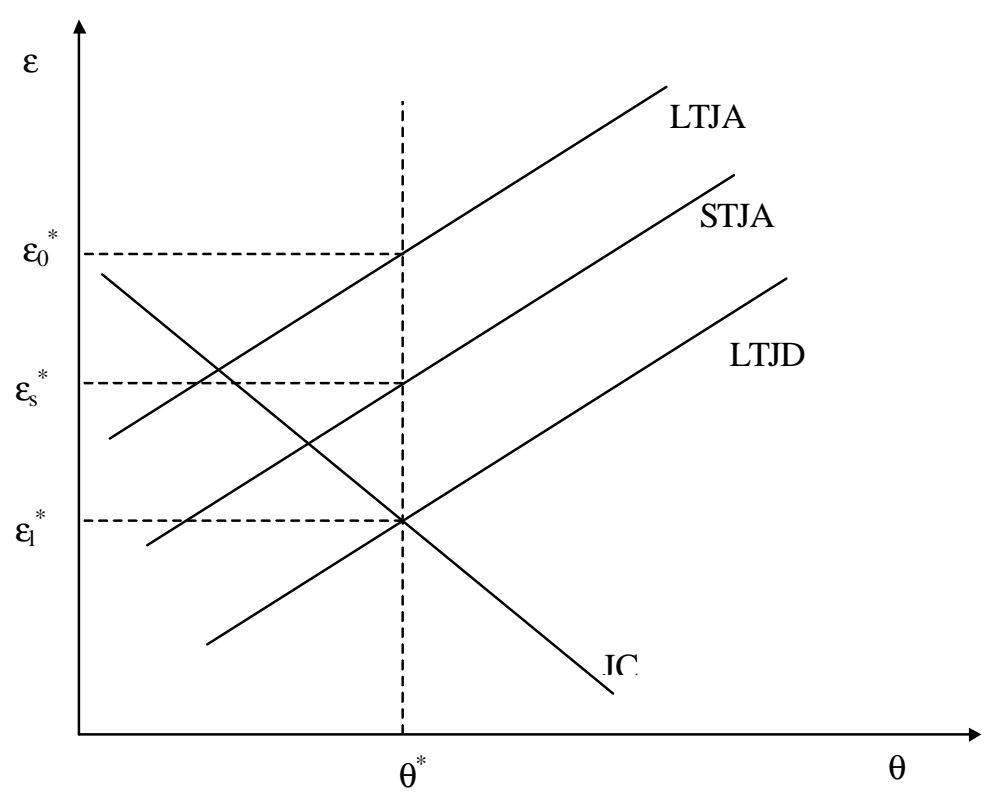

Figure 2: Job creation and job destruction

assumed constant and normalized to unity-, a fraction $p\left[1-\Phi\left(\varepsilon_{s}^{*}\right)\right]$ of which gives rise to fixedduration contracts and a fraction $(1-p)\left[1-\Phi\left(\varepsilon_{\mathbf{0}}^{*}\right)\right]$ to long-term jobs. At date $t$, the number of fixed-duration jobs is thus exactly $p\left[1-\Phi\left(\varepsilon_{s}\right)\right] \cdot m(u, v)$. Among those jobs, those with productivity lower than $\varepsilon_{0}^{*}$ are necessarily destroyed if they are not hit by a shock. Moreover, a fraction $\lambda \Phi\left(\varepsilon_{0}^{*}\right)$ of those jobs is destroyed every period (those that are hit by a shock making their productivity fall short of the critical level $\varepsilon_{\mathbf{0}}^{*}$ ). Thus, the total number of short-term jobs destroyed (i.e. not converted into long-term jobs) in period $t$ is given by:

$$
p m(u, v) \cdot\left\{(1-\lambda)\left[\Phi\left(\varepsilon_{0}^{*}\right)-\Phi\left(\varepsilon_{s}^{*}\right)\right]+\lambda \Phi\left(\varepsilon_{0}^{*}\right)\left[1-\Phi\left(\varepsilon_{s}^{*}\right)\right]\right\}
$$

Similarly, the number of long-term jobs at date $t$ is $1-u-p\left[1-\Phi\left(\varepsilon_{s}^{*}\right)\right] \cdot m(u, v)$, (total employment less the total number of operating short-term jobs), a fraction $\lambda \Phi\left(\varepsilon_{l}^{*}\right)$ of which is terminated every period. Equating the flows of recruiting and dismissals and rearranging a bit finally gives the steady-state unemployment rate:

$$
u^{*}=\frac{\lambda \Phi\left(\varepsilon_{l}^{*}\right)}{\lambda \Phi\left(\varepsilon_{l}^{*}\right)+\theta^{*} q\left(\theta^{*}\right) \cdot\left\{\lambda \Phi\left(\varepsilon_{l}^{*}\right) p\left[1-\Phi\left(\varepsilon_{s}^{*}\right)\right]+\left[1-\Phi\left(\varepsilon_{0}^{*}\right)\right]\left[1-\lambda p \Phi\left(\varepsilon_{s}^{*}\right)\right]\right\}}
$$

As in the conventional Mortensen and Pissarides (1994) model, $u^{*}$ increases with the cutoff productivity $\varepsilon_{l}$ at which long-term jobs are destroyed. Naturally, unemployment also rises when more 
fixed-duration contracts are destroyed every period, so that $u^{*}$ also increases with the threshold productivity $\varepsilon_{\mathbf{0}}$. Also note that $u^{*}$ increases ceteris paribus with the proportion of short-term contracts $p$. This proportion has a direct positive impact on unemployment (see the denominator of (15)) since, in the presence of positive firing costs, short-term jobs are destroyed more often than long-term jobs $\left(\varepsilon_{\mathbf{0}}>\varepsilon_{l}\right)$.

\section{Comparative statics: Employment policy and aggregate shocks}

\subsection{Qualitative analysis}

We are interested in the combination of two policy instruments, namely the extent of firing restrictions, as measured by $f^{7}$, and the proportion of fixed-duration contracts, $p$. We begin by analyzing the impact of the former. The impact on job creation and job destruction of an increase in $f$ is summarized in the following proposition, and illustrated on figure 3 :

Proposition 1 An increase in $f$

(i) shifts the LTJD schedule downward, i.e. reduces long-term job destruction for a given $\theta$;

(ii) shifts the LTJA schedule upward, i.e. intensifies short-term job destruction for a given $\theta$;

(iii) shifts the STJA schedule upward, i.e. reduces short-term job creation for a given $\theta$;

(iv) shifts the JC schedule to the left, i.e. reduces labor market tightness for given patterns of job destruction $\left(\varepsilon_{l}\right.$ and $\left.\varepsilon_{0}\right)$.

The proof of this proposition is in the appendix. The intuition behind points (i) and (iii) is well-known (see e.g. Mortensen and Pissarides, 1997 for a recent account). Higher firing costs limit job destruction by making layoffs more expensive, while they also inhibit job creation by reducing the overall expected profitability of jobs. The novelty here is point (ii): More stringent restrictions on the termination of long-term contracts induce less frequent transformation of fixed-duration jobs into long-term jobs because more expensive termination of the latter has to be balanced by a better productivity.

From proposition 1, it appears that the overall impact on the equilibrium values $\theta^{*}, \varepsilon_{l}^{*}, \varepsilon_{s}^{*}, \varepsilon_{0}^{*}$ and $a$ fortiori $u^{*}$ are qualitatively ambiguous. We thus postpone their analysis to the quantitative experiments below.

\footnotetext{
${ }^{7}$ Note at this point that the nature of this firing cost is of some importance. It is well-known that, under the assumption of efficient surplus sharing between the worker and the firm, the only thing that matters is the net cost of separation. There would be no employment effect of a transfer from the firm to the worker contingent on separation in our environment, since it would leave total match surplus unaffected. Such a transfer would be entirely absorbed by wage reductions (see e.g. Burda, 1992). Of course, this argument would collapse if wage reductions were only possible to a limited extent, e.g. because of an institutional constraint.
} 


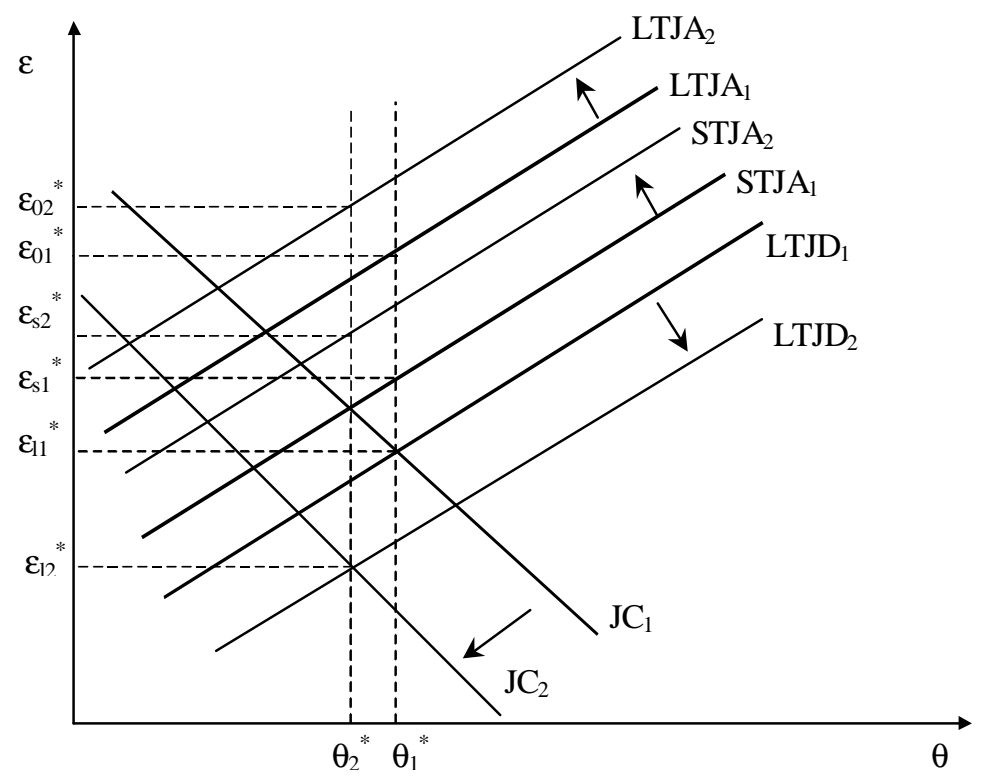

Figure 3: Comparative statics: Raising firing costs

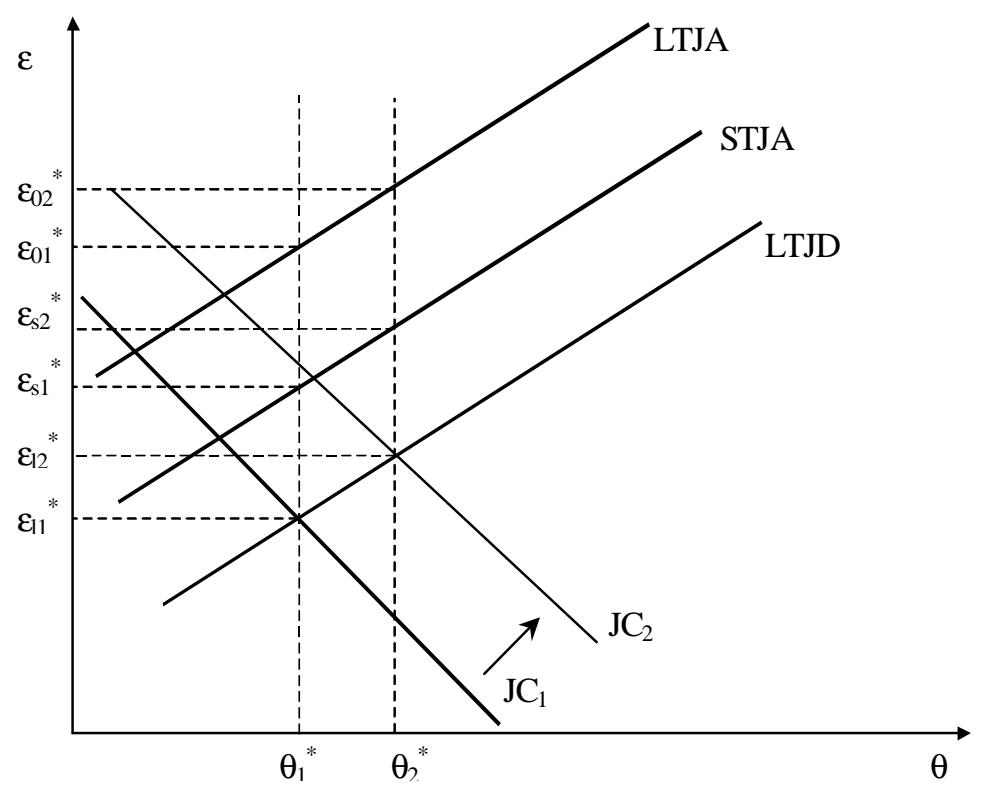

Figure 4: Comparative statics: Raising the share of fixed-duration contracts 
The impact of raising the proportion of fixed-duration contracts $p$ is as follows (see also figure 4):

Proposition 2 An increase in the proportion of fixed-duration contracts leaves the job destruction and job acceptance behavior unaffected and shifts the JC schedule to the right: for given patterns of job destruction and job acceptance, introducing more fixed-duration contracts encourages job creation.

In equilibrium, both job creation and job destruction increase:

$$
\frac{\partial \theta^{*}}{\partial p}>0, \quad \frac{\partial \varepsilon_{l}^{*}}{\partial p}>0, \quad \frac{\partial \varepsilon_{0}^{*}}{\partial p}>0 \quad \frac{\partial \varepsilon_{s}^{*}}{\partial p}>0
$$

and so does the welfare of unemployed workers.

This proposition is straightforward from the expressions of (LTJD), (LTJA), (STJA) and (JC), and a graphical analysis (see figure 3 ).

Again, the intuition behind proposition 2 is simple: Since fixed-duration jobs yield a higher surplus than long-term jobs, increasing the proportion of the former fosters jobs creation. Increased job creation in turn makes agents more exacting about the minimum acceptable productivity of their jobs by raising the opportunity cost of every match. Hence more intense job turnover.

Since both job creation and job destruction increase in equilibrium, the impact of a rise in $p$ on the rate of unemployment is ambiguous. However, the rise in equilibrium tightness $\theta^{*}$ tends to make the unemployed workers better off, simply by raising their job contact rate and thereby their option value of search. Finally, since an increase in the approval rate of fixed-term jobs increases total job destruction (proposition 2), it also raises the per period transfer $\sigma$ for a given value of the employment protection tax $f$. Introducing more fixed-duration jobs thus unambiguously makes the unemployed better off. Concerning the other categories of workers, an increase in the proportion of fixed-duration contracts has an ambiguous impact on the welfare of the employed, whatever the type of job they hold. On the one hand, they are better off because the welfare of unemployed workers is improved, which allows them to get higher wages through the bargaining process. On the other hand, their job loss probability is increased.

\subsection{Numerical exercises}

We now try a rough calibration of our model to evaluate the relative strength of the counteractive effects we pointed out in the previous subsection. For the sake of simplicity, as for realism, we adopt the following constant returns, Cobb-Douglas matching function $m(u, v)=M \cdot u^{\eta} \cdot v^{1-\eta}$ (see 
e.g. Blanchard and Diamond, 1989, for evidence on U.S. data). The distribution of productivity shocks is taken uniform over $[\underline{\varepsilon}, \bar{\varepsilon}]$, i.e. $\Phi(\varepsilon)=(\varepsilon-\underline{\varepsilon}) /(\bar{\varepsilon}-\underline{\varepsilon})$. The baseline parameter values that we use are reported in Table 4. They are chosen so as to match a 'typical European economy' for values of the policy parameters $p$ and $f$ in a reasonable range. The basis period is taken to be six months, a typical duration for a fixed-term contract. Note that the workers' share of the match surplus, $\gamma$, equals the elasticity of the matching function, $\eta$, a configuration which is known to ensure constrained efficiency in the economy without firing costs or fixed duration jobs (Mortensen and Pissarides, 1999). The value of unemployment income is set to 0.35 . Given that the average wage is about 0.7 , the replacement ratio amounts to 0.5 . This fairly high value is supposed to portray the situation of low-skilled workers in Western Continental Europe (see Mortensen and Pissarides, 1999).

Table 4: Baseline parameter values

\begin{tabular}{cccccccc}
\hline \hline$z$ & $\beta$ & $\lambda$ & $\gamma$ & $h$ & {$[\underline{\varepsilon}, \bar{\varepsilon}]$} & $M$ & $\eta$ \\
.35 & .975 & .3 & .5 & .001 & {$[-.1,1]$} & .15 & .5 \\
\hline \hline
\end{tabular}

To quantify the effects of policy, we obviously let $p$ cover $[0,1]$ and $f$ vary between 0 and 1 semester of average output. The relevance of this range will be discussed below. The responses to these variations of the mean unemployment spell duration, the destruction rate of long- and shortterm jobs, the share of fixed-term jobs in total employment and the long-run rate of unemployment are reported on panels $a$ through $e$ of Figure $5^{8}$. We see from this Figure that our model economy matches real world orders of magnitude reasonably well in most cases. The unemployment rate varies around 16\% (recall that we are supposedly looking at unskilled workers), and temporary jobs account for something between 0 and $15 \%$ of total employment, which is in line with the evidence reported in Table 3. The average duration of a long-term job is roughly 6 to 10 years (depending on the policy parameters). The average unemployment spell duration is something between 6 and 9 months.

\subsubsection{Quantity analysis}

First, we see that the findings of Mortensen and Pissarides (1997) on the overall effects of firing costs on unemployment in the absence of fixed-duration jobs are confirmed. Looking at the line $p=0$ on

\footnotetext{
${ }^{8} \mathrm{On}$ all panels, $f$ is on the $x$-axis, $p$ is on the $y$-axis and the variable of interest is on the $z$-axis. The rates of destruction of the various types of jobs are expressed as fractions of the source population, i.e. they are defined as the ratio of the total number of jobs of one particular type destroyed in the period to the total number of such jobs operating in the period. The unit of measure for firing costs is one semester of average output.
} 

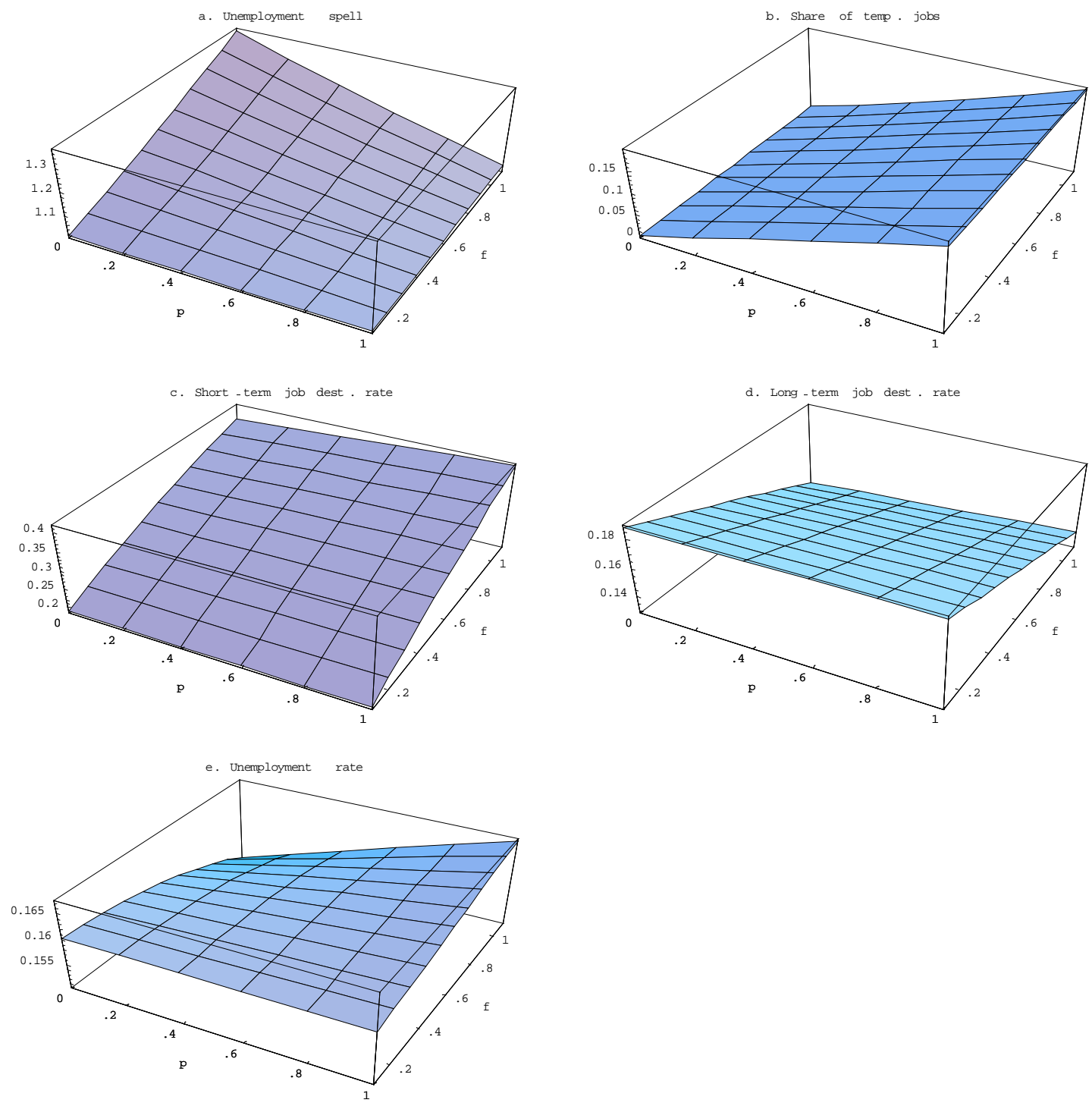

Figure 5: Quantities 
panel $e$ of Figure 5, we see that, even though more stringent firing restrictions have limiting effects on both job creation and job destruction, the latter seems to overcome the former, so that steadystate unemployment drops with higher firing costs. Second, and more important, firing costs are less efficient, the more you allow for fixed-duration jobs to be created. Otherwise stated, an increase in the approval rate of fixed-term contracts increases unemployment at any given (positive ${ }^{9}$ ) level of firing restrictions. This result is intuitive, since firing costs apply to long-term jobs only. Because agents prefer temporary jobs, allowing for more of them to be formed reduces the scope of firing restrictions. Moreover, firing costs increase the destruction rate of short-term jobs. Figure 5e also suggests that this effect can be quite strong: In the presented numerical exercise, the sign of the effect of employment protection on unemployment is reversed by the introduction of fixed-term jobs. Indeed, for $p=1$, firing restrictions actually encourage the turnover of fixed-term jobs to such an extent that they actually increase unemployment. Heavy firing costs render long-term jobs less profitable, so that a lesser share of fixed-duration contracts are perpetuated, which spurs job destruction. As a result, unemployment ends up being higher in the case $p=1$ (no restriction on determined duration contracts) and $f=1$ (substantial firing restrictions) than in the laissez-faire case $(p, f)=(0,0)$. Finally, it may be worthwhile pointing out that, even though the sign of the combined effect of our two policy tools on long-run unemployment seems to be ambiguous, its size is only significant (in either direction) for fairly large values of the firing cost.

Concerning the impact of our two policy tools on job flows, we first see from panels $c$ and $d$ of Figure 5 that for any level of (positive) firing costs, raising the 'approval rate' of short-term jobs $p$ increases the propensity to destroy both types of jobs (which confirms proposition 2). We also obtain (although the graphs are not reported here) that the labor market tightness ratio $\theta^{*}$ and the productivity requirement for short-term jobs $\varepsilon_{s}^{*}$ both increase with $p$. As a result, the introduction of fixed-duration contracts increases job turnover for any given level of employment protection. Moreover, as intuition suggested, this effect of fixed-term contracts is more pronounced for high levels of employment protection. Symmetrically, it clearly appears that firing restrictions slow down the destruction of long-term jobs at all values of $p$, but are less efficient in doing so for high approval rates.

\footnotetext{
${ }^{9}$ Obviously, there is no effect of raising $p$ when $f=0$, since in the absence of any firing restrictions, the distinction between the two types of jobs is simply irrelevant.
} 


\subsubsection{Welfare and political economy}

We now turn to the welfare implications of the simultaneous use of firing restrictions and determined duration contracts. Given that all agents are risk-neutral in the model, and ignoring all possible costs of redistribution, a simple and consistent aggregate welfare criterion is a measure of the economy's total output net of the recruiting costs. A precise formula for this criterion is derived in the Appendix. Panel $e$ on Figure 6 plots the reaction of that criterion to a set of possible reforms consisting of giving to $p$ and $f$ any value in the above specified range, starting from a laissez-faire situation (i.e. $p=0, f=0$ ). What those plots show is that policy is costly in terms of aggregate welfare since agents are worse off 'on average' after the reform than in the laissez-faire economy. This is hardly surprising, since we know that the laissez-faire economy is constrained-efficient under the restriction $\gamma=\eta$. More informative is the fact that the introduction of fixed-term jobs partially corrects the welfare loss due to firing restrictions. Not enough, however, to fully restore efficiency.

So far, our analysis does not explain the simultaneous implementation of firing restrictions and fixed-term jobs that crowd out their impact on job destructions. Our numerical experiments suggest that there is no point in introducing both firing cost and fixed-term jobs, since it systematically decreases welfare and increases unemployment. A benevolent social planner would thus never choose such a combination of labor market policy tools, at least for the retained set of parameter values that is supposed to picture a typical European economy. However, looking at the consequences of this combination on the welfare of every type of worker sheds some light on this issue. Panels $a$ through $d$ of Figure 6 show how the individual workers' value functions $V^{u}, V^{s}(\varepsilon), V^{0}(\varepsilon)$, and $V^{l}(\varepsilon)$ react to the above described reforms. ${ }^{10}$ Surprisingly, introducing both firing restriction and fixed-term jobs improve the well-being of every type of worker. ${ }^{11}$ This is compatible with a decrease in aggregate welfare because labor market regulation also influences the composition of jobs and unemployment, as well as aggregate profits. For instance, we see on Figure $6 a$ that a larger share of temporary jobs improves the welfare of the unemployed. This in turn has a positive effect on the welfare of every type of worker, since the value of unemployment $V^{u}$ is always the worker's 'threat point' in the bargaining programme. Our numerical exercise shows that this effect is sufficiently strong to make every type of worker better off although their job loss probability is increased.

\footnotetext{
${ }^{10}$ Note as a technical point that all components of our welfare criteria $\left(V^{u}, V^{s}, V^{0}\right.$, and $\left.V^{l}\right)$ are 'jump' variables that exhibit no transitional dynamics, save for the lump-sum transfer $\sigma$, which is proportional to total long-term job destruction, and therefore does not directly jump onto its steady-state value. The reported simulations take this dynamic effect into account.

${ }^{11}$ The reported value functions are those of workers holding jobs with the highest possible productivity $\bar{\varepsilon}$. Taking different values of $\varepsilon$ merely changes the levels, not the shape of the plots.
} 
Similarly, firing restrictions are beneficial-up to a point - to each type of worker, the preferred value of the firing cost depending on the particular worker type. At the aggregate level, however, positive firing costs cause the survival of low productivity jobs that diminish aggregate welfare.

From a political economy perspective, these results mean that there might be a majority of workers to support a combination of stringent firing restrictions and fixed-term jobs on labor markets, a fact that may explain the very existence of this type of combination in some countries. Consider an economy with an initially unregulated labor market: $p=0$ and $f=0$. The first four panels on Figure 6 show that it is in the interest of a majority of workers to militate for the implementation of a reform consisting in assigning to $p$ and $f$ positive values. Indeed, any worker whose job is not directly threatened by such a reform will be in favor of it. ${ }^{12}$ This includes all the unemployed and all long-term job holders, which clearly makes a majority.

Moreover, employees holding permanent jobs prefer the highest level of job protection. For those workers, who play a major role in the political process governing labor market legislation, ${ }^{13}$ the preferred situation is a maximal approval rate for temporary jobs, and firing costs of an amount coming close to 3 months of the average production of a worker. Panel $g$ shows that a trade union maximizing the aggregate discounted income of all workers would support approximately the same platform - with a slightly lower level of firing costs. ${ }^{14}$

The above analysis ignored profits. Looking at profits (panel $f$ of Figure 6), it appears that they decline with both $p$ and $f$. The fact that profits are a decreasing function of firing costs is no big surprise. Concerning the impact of $p$, it is the sum of two counteracting effects. On one hand, raising $p$ facilitates the opening of more profitable jobs. On the other hand, it also increases the job finding rate, which strengthens the workers' position in the wage negotiation and thus increases wage pressure. The latter effect turns out to overcome the former.

Bearing this in mind, one can think that the identity (and political weight) of profit earners matters in the process governing the adoption of employment protection rules, and that profits therefore shouldn't be absent from the analysis. Assuming, as we implicitly did so far, that the share of profits earned by workers is zero amounts to assuming that equity ownership is concen-

\footnotetext{
${ }^{12} \mathrm{By}$ a direct threat we refer to the following type of situation: A worker employed e.g. on a short-term job with a value of $\varepsilon$ larger than but close to the current threshold $\varepsilon_{s}^{*}$ would loose his job with certainty-i.e. even without an adverse shock-if positive firing costs are introduced, because what this introduction does is raise the productivity cutoff $\varepsilon_{s}^{*}$. The reform would therefore cause this worker to change categories-to become unemployed, in this case-which would obviously make him worse off.

${ }^{13}$ In our model economy, the median voter obviously belongs to this category.

${ }^{14}$ Abowd and Kramarz (2000) estimate that the cost of a layoff for economic causes in France amounts to $126 \%$ of the annual cost of labor, with a large share of this cost corresponding to direct transfers from firms to workers.
} 

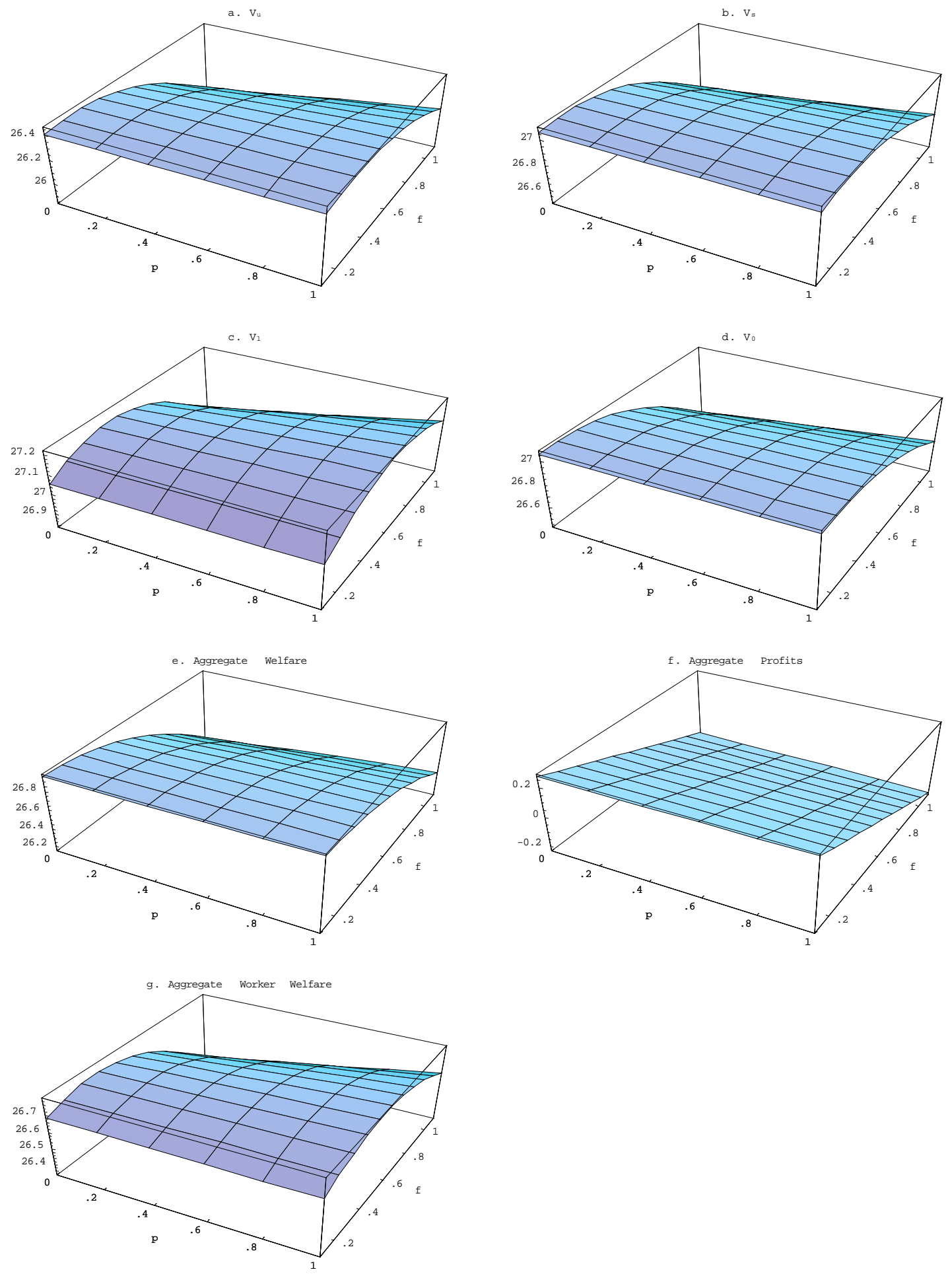

Figure 6: Welfare when profits are not distributed to workers 

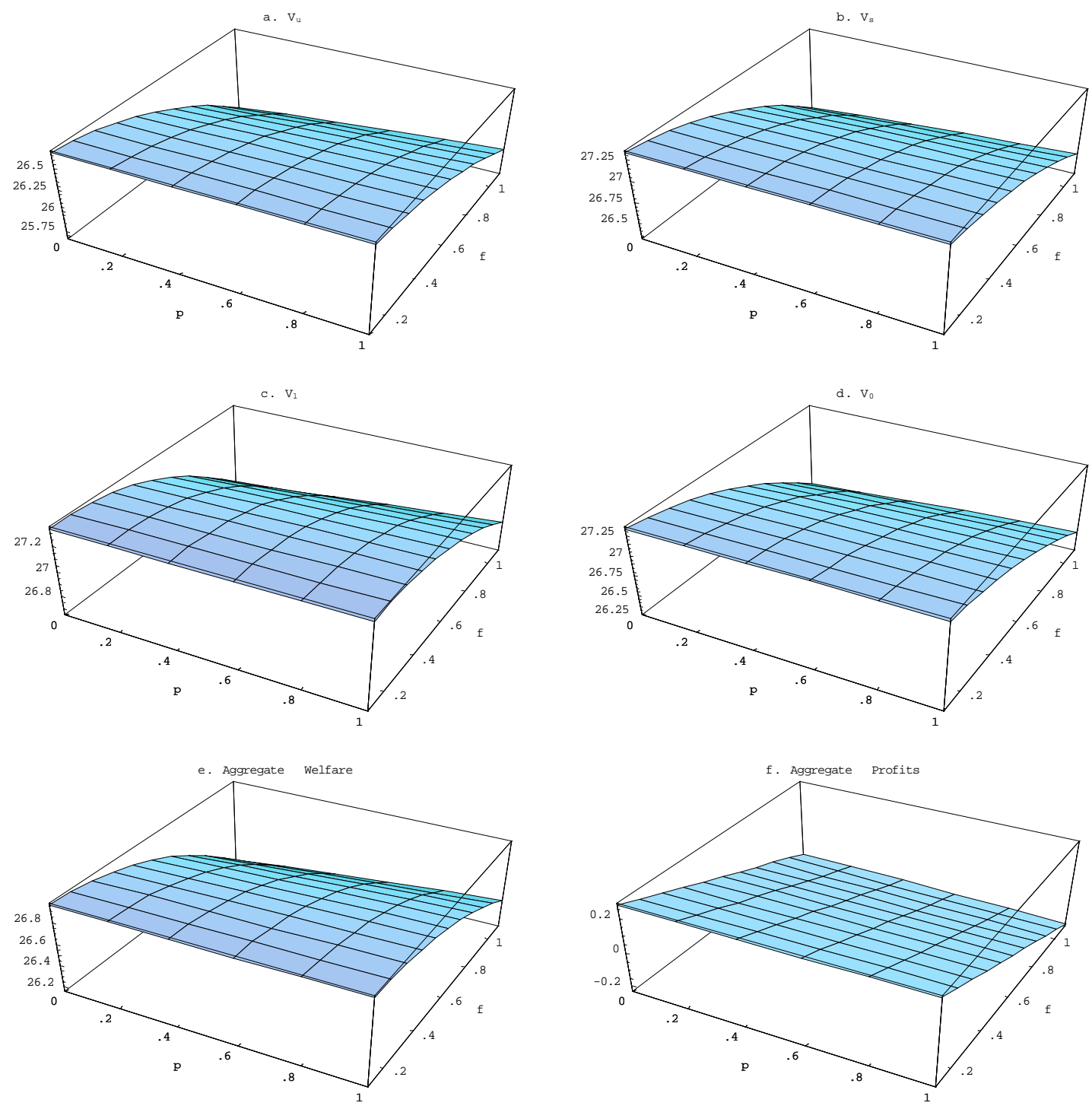

Figure 7: Welfare when profits are evenly distributed 
trated among a few shareholders who do not participate in the labor market. The opposite case of extreme dispersion in firm ownership corresponds to a situation where profits are evenly distributed to workers. Figure 7 plots the welfare functions of the various categories of workers under this alternative assumption.

A glance at this last Figure shows that the situation is very different form that of Figure 6. If all workers get an equal share of aggregate profits, then firing restrictions find virtually no political support in our model economy. ${ }^{15}$ It is interesting to think of the contrast between the two situations in relation with the common view that corporate ownership is relatively more dispersed in AngloSaxon economies than in continental Europe (see e.g. La Porta et al., 1999, European Corporate Governance Network, 1997), even though comparable measures of ownership concentration are hard to construct (ECGN, 1997). As we documented in Section 2 (Tables 1 and 2), Anglo-Saxon economies also appear to have the least regulated labor markets. Our model is consistent with both observations, and suggests that there might be a link between them. Specifically, it suggests that the structure of corporate ownership might have a bearing on labor market regulations, if one admits that the latter are largely the outcome of a political process.

\section{Conclusion}

The search and matching model used in this paper shows that the combined effects of stringent dismissal restriction policies and the spread in temporary jobs may be very different from those usually expected. Facilitating hires on temporary contracts is generally thought of as a means to foster job creation and cut unemployment. Our model shows that, while it indeed fosters job creation, its beneficial impact on employment can be offset by the increase in job turnover when there are positive firing costs. Trying to achieve more labor market flexibility through spreading temporary jobs without reducing firing costs may thus be both inefficient in terms of aggregate welfare and a poor weapon to fight unemployment.

In spite of its aggregate inefficiency, the combination of temporary contracts and firing restrictions on permanent jobs may be beneficial to a majority of individual workers. In particular, this is the case if corporate ownership is sufficiently concentrated, implying that the share of profits distributed to workers is small. We believe the structure of firm ownership in continental Europe to be suitably stylized by this assumption. Taking this for granted, we thus find that, contrary to

\footnotetext{
${ }^{15}$ Even though it is not evident from the Figure, numerical tables show that workers employed on permanent jobs reach their maximum utility for $p=1$ and a slightly positive value of $f(.1$ or so). All other worker types prefer $(p, f)=(0,0)$.
} 
what is often argued, the culprit for high European unemployment rates is not so much the political support to firing restrictions per se: It is now well known, and again confirmed in our model that firing restrictions may or may not cut unemployment, their impact being very limited in either direction. Rather, our analysis suggests that it is the support to the combination of two instruments with opposite effects on job destruction and job creation-namely, job security provisions and determined duration jobs - that increases unemployment and deteriorates welfare.

\section{References}

[1] Abowd, J., Corbel, P. and F. Kramarz (1999), "The entry and exit of workers and the growth of employment: an analysis of French establishments", Review of Economics and Statistics, 81, 170-187.

[2] Abowd, J. and F. Kramarz, (2000), "The Costs of Hiring and Separations," working paper, CREST-INSEE.

[3] Addison, J.T. and W.S. Siebert (1993), "The U.K.: Labour Market Institutions, Law and Performance", chapter 11, in Hartog, J. and J. Theeuwes, Labour Market Contracts and Institutions, A Cross-National Comparison, Amsterdam: North-Holland.

[4] Aguirregabiria, V. and C. Alonso-Borrego (1999), "Labor Contracts and Flexibility: Evidence from a Labor Market Reform in Spain", Working Paper, University of Chicago.

[5] Barthelemy, N. and C. Jaulent (1997), "Les mouvements de main-d'œuuvre dans les établissements de 10 salariés ou plus au premier semestre 1996", Premières Synthèses, 20-2, Ministère du Travail et des Affaires Sociales, DARES.

[6] Bentolila, S. and G. Bertola (1990), "Firing Costs and Labour Demand: How Bad is Eurosclerosis", Review of Economic Studies, 57, 381-402.

[7] Bentolila, S. and J. J. Dolado (1994), "Labour Flexibility and Wages: Lessons from Spain", Economic Policy, 14, 53-99.

[8] Bentolila, S. and G. Saint-Paul (1992), "The Macroeconomic Impact of Flexible Labor Contracts, With An Application to Spain", European Economic Review, 36, 1013-53.

[9] Bertola, G. (1990), "Job Security, Employment and Wages", European Economic Review, 34, $851-86$. 
[10] Blanchard, O. J. and P. A. Diamond (1989), "The Beveridge Curve", Brookings Papers on Economic Activity, 1, 1-76.

[11] Blanchard, O. J. and A. Landier (2000), "The Perverse Effects of Partial Labor Market Reform: Fixed Duration Contracts in France", mimeo, MIT.

[12] Boeri, T. (1999) "Enforcement of Employment Security Regulations, On-the-job Search and Unemployment Duration", European Economic Review, 43, 65-89.

[13] Cabrales, A. and H.A. Hopenhayn (1997), "Labor-market Flexibility and Aggregate Employment Volatility", Carnegie-Rochester Conference Series on Public Policy, 46, 189-228.

[14] European Corporate Governance Network, 1997, The Separation of Ownership and Control: A Survey of 7 European Countries, Preliminary report to the European Commission, Brussels: European Corporate Governance Network. (www.ecgn.elb.ac.be/ecgn/eurprelimreport.htm).

[15] Garibaldi, P. (1998), "Job Flow Dynamics and Firing Restrictions", European Economic Review, 42, pp. 245-275.

[16] Garibaldi, P. and G. Violante, (1999), "On the Neutrality of Severance Payments in the Theory of Search and Unemployment", mimeo, IMF.

[17] Conseil Supérieur de l'Emploi, des Revenus et des Coûts (CSERC) (1996), Inégalités d'Emploi et de Revenu : les Années 90, Paris : la Documentation Française.

[18] Goux, D. and E. Maurin, (2000), "Labor Market Institutions and Job Stability. A Firm-Level Analysis of Layoff Risk for High and Low-Seniority Workers", working paper n²000 - 29, CREST-INSEE.

[19] Grubb, D. and W. Wells (1993), "Employment Regulation and Pattern of Work in EC Countries", OECD Economic Studies, 21, pp. 7-59.

[20] La Porta, R., Lopez-De-Silanes, F. and A. Shleifer (1999) "Corporate Ownership Around the World", Journal of Finance, 54 (2), 471-517.

[21] Ljungqvist, L. (1998), "How Do Layoff Costs Affect Employment?", Manuscript, Handelshögskolan i Stockholm. 
[22] Millard, S. and D. Mortensen, (1997), "The Unemployment and Welfare Effects of Labour Market Policy : a Comparison of the USA and the UK", in Snower, D. and G. de la Dehesa (eds), Unemployment Policy: Governement Options for the Labour Market, CEPR, Cambridge University Press.

[23] Mortensen, D. T. and C. A. Pissarides (1994), "Job Creation and Job Destruction in the Theory of Unemployment", Review of Economic Studies, 61, 397-415.

[24] Mortensen, D. T. and C. A. Pissarides (1999), "New Developments in the Models of Search in the Labor Market", mimeo Northwestern University.

[25] Mortensen, D. T. and C. A. Pissarides (1999), "Unemployment Responses to 'Skill-Biased' Technology Shocks : the Role of Labour Market Policy", Economic Journal, 109, 242-65.

[26] OECD (1999), Employment Outlook, Paris: OECD.

[27] OECD (1994), Jobs Study: Implementing the Strategy, Paris: OECD.

[28] Rogowski, R. and K. Schöman, (1996), "Legal Regulation and Flexibility of Employment Contracts", chapter 21, in Schmid, G., J.O'Reilly and K. Schöman (eds) International Handbook of Labour Market Policy and Evaluation, Brookfield: Edward Elgar.

[29] Saint-Paul, G. (1996), Dual Labor Markets, Cambridge, MA.: The MIT Press.

[30] Wasmer, E. (1999). "Competition for Jobs in a Growing Economy and the Emergence of Dualism in Employment", Economic Journal, 109, 349-371.

\section{APPENDIX}

\section{A Proof of Proposition 1}

- Point (ii): Differentiating (LTJD) with respect to $\varepsilon_{l}$ and $f$, one gets:

$$
\left.\frac{d \varepsilon_{l}}{d f}\right|_{\theta=\mathrm{const}}=-\frac{(1-\beta)[1-\beta(1-\lambda)]}{1-\beta\left[1-\lambda \Phi\left(\varepsilon_{l}\right)\right]}<0 .
$$

- Point (ii): Differentiating (LTJA) with respect to $\varepsilon_{0}, \varepsilon_{l}$ and $f$, one gets, with (16):

$$
\left.\frac{d \varepsilon_{0}}{d f}\right|_{\theta=\mathrm{const}}=\left.\frac{d \varepsilon_{l}}{d f}\right|_{\theta=\mathrm{const}}+1-\beta(1-\lambda)=\frac{\beta \lambda \Phi\left(\varepsilon_{l}\right)[1-\beta(1-\lambda)]}{1-\beta\left[1-\lambda \Phi\left(\varepsilon_{l}\right)\right]}>0 .
$$

- Point (iii): Substituting (LTJA) into (STJA) yields, after some rearrangements: 


$$
\varepsilon_{s}=\varepsilon_{0}-\frac{\beta \lambda}{1-\beta(1-\lambda)} \int_{\varepsilon_{l}}^{\varepsilon_{0}} \Phi(x) d x .
$$

Differentiating (18) with respect to $\varepsilon_{s}, \varepsilon_{0}, \varepsilon_{l}$ and $f$, one gets, with (16) and (17):

$$
\begin{aligned}
\left.\frac{d \varepsilon_{s}}{d f}\right|_{\theta=\mathrm{const}} & =\left.\frac{d \varepsilon_{0}}{d f}\right|_{\theta=\mathrm{const}}-\frac{\beta \lambda}{1-\beta(1-\lambda)} \cdot\left[\left.\Phi\left(\varepsilon_{0}\right) \cdot \frac{d \varepsilon_{0}}{d f}\right|_{\theta=\mathrm{const}}-\left.\Phi\left(\varepsilon_{l}\right) \cdot \frac{d \varepsilon_{l}}{d f}\right|_{\theta=\mathrm{const}}\right] \\
& =\frac{(\lambda \beta)^{2} \cdot \Phi\left(\varepsilon_{l}^{*}\right) \cdot\left[1-\Phi\left(\varepsilon_{0}^{*}\right)\right]}{1-\beta\left[1-\lambda \Phi\left(\varepsilon_{l}^{*}\right)\right]}>0 .
\end{aligned}
$$

- Point (iv) is immediate from the expression of (JC).

\section{B Total output and welfare}

Counting the operating jobs of each category and summing their individual per period output over the relevant range of productivity parameters yields total per period market output $Q_{t}$ in the economy. Since, due to matching frictions, the unemployment rate is a non-jump variable, account has to be taken of its dynamics when computing $Q_{t}$.

$$
\begin{array}{rlrl}
Q_{t}= & u_{t-1} \cdot \theta^{*} q\left(\theta^{*}\right) \cdot\left[p \int_{\varepsilon_{s}^{*}}^{\bar{\varepsilon}} x d \Phi(x)+(1-p) \int_{\varepsilon_{0}^{*}}^{\bar{\varepsilon}} x d \Phi(x)\right] & \text { (jobs of both types created in the period) } \\
& +u_{t-2} \cdot \theta^{*} q\left(\theta^{*}\right) \cdot\left[1-\lambda \Phi\left(\varepsilon_{s}^{*}\right)\right] \cdot p \int_{\varepsilon_{0}^{*}}^{\bar{\varepsilon}} x d \Phi(x) & & \text { (transformed short-term jobs) } \\
& +\widetilde{Q}_{t}, & & \text { (long-term jobs operating since }
\end{array}
$$

where $\widetilde{Q}_{t}$ is the output produced by long-term jobs operating as such since at least two periods. It has dynamics of its own, which we now characterize.

The mass of long-term jobs operating as long term jobs since at least two periods is obtained as follows. Let us define by $n_{t}(x)$ the measure of such jobs with productivity $x$. It solves the following equation:

$$
\begin{aligned}
n_{t}(x)= & (1-\lambda) \cdot n_{t}(x) \\
& +(1-\lambda) \cdot n_{t-1}^{0}(x) \\
& +\left[1-u_{t-1}-u_{t-2} \cdot \theta^{*} q\left(\theta^{*}\right) \cdot p \cdot\left[1-\Phi\left(\varepsilon_{s}^{*}\right)\right]\right] \cdot \lambda \phi(x) .
\end{aligned}
$$

(long-term jobs operating since at least two periods
in previous period that keep the same productivity $x$ )
(new long-term jobs in previous period
that keep the same productivity $x$ )
(long-term jobs operating in previous period hit by
a productivity shock $x$ )

and $n_{t-1}^{0}(x)$ amounts to the sum of new long-term jobs with productivity $x$ created in previous period and of short-term jobs that were converted into long-term jobs with productivity $x$ in previous period:

$$
\begin{aligned}
n_{t-1}^{0}(x)= & u_{t-3} \cdot \theta^{*} q\left(\theta^{*}\right) \cdot p \cdot(1-\lambda) \cdot \phi(x) & & \text { (ex-short-term jobs created with productivity } x \\
& +u_{t-3} \cdot \theta^{*} q\left(\theta^{*}\right) \cdot p \cdot\left[1-\Phi\left(\varepsilon_{s}^{*}\right)\right] \cdot \lambda \phi(x) & & \text { that have not been hit by a shock) } \\
& +u_{t-2} \cdot \theta^{*} q\left(\theta^{*}\right) \cdot(1-p) \cdot \phi(x) . & & \text { productivity shock } x \text { ) }
\end{aligned}
$$


Substituting (21) into $(20)$ and summing individual outputs over $\left[\varepsilon_{0}^{*}, \bar{\varepsilon}\right]$ for $n_{t-1}^{0}(x)$ and over $\left[\varepsilon_{l}^{*}, \bar{\varepsilon}\right]$ for $n_{t}(x)$, yields a dynamic equation defining $\widetilde{Q}_{t}$ :

$$
\begin{aligned}
\widetilde{Q}_{t}=(1-\lambda) \cdot \widetilde{Q}_{t-1}+(1-\lambda) \cdot\left[u_{t-3} \cdot p \cdot[\right. & \left.\left.1-\lambda \Phi\left(\varepsilon_{s}^{*}\right)\right]+u_{t-2} \cdot(1-p)\right] \cdot \theta^{*} q\left(\theta^{*}\right) \cdot \int_{\varepsilon_{0}^{*}}^{\bar{\varepsilon}} x d \Phi(x) \\
& +\lambda \cdot\left[1-u_{t-1}-u_{t-2} \cdot \theta^{*} q\left(\theta^{*}\right) \cdot p \cdot\left[1-\Phi\left(\varepsilon_{s}^{*}\right)\right]\right] \cdot \int_{\varepsilon_{s}^{*}}^{\bar{\varepsilon}} x d \Phi(x) .
\end{aligned}
$$

The latter equation, together with (19), characterizes the dynamics of aggregate output.

Aggregate welfare is then measured by

$$
W=\sum_{t=0}^{+\infty} \beta^{t} \cdot\left(Q_{t}+z u_{t}-h \theta u_{t}\right)
$$

which is the present discounted sum of total market production, plus that of the unemployed, net of total recruiting costs. 


\section{IZA Discussion Papers}

\section{No Author(s)}
171 C. Dustmann
F. Windmeijer
172
D. Card

173

174

175

176

O. Hübler

W. Meyer

177 B. R. Chiswick

G. Repetto

178 R. Euwals

M. Ward

179 E. Wasmer

P. Weil

180 T. K. Bauer

I. N. Gang

181 E. Wasmer

Y. Zenou

182 M. Fertig

C. M. Schmidt

183 M. Fertig

C. M. Schmidt

184 M. Corak

B. Gustafsson

T. Österberg

185 H. Bonin

K. F. Zimmermann
Titel

Area

Date

Wages and the Demand for Health - A Life Cycle

5

Analysis

Reforming the Financial Incentives of the Welfare

System

Timing, Togetherness and Time Windfalls

5

$7 / 00$

Does Money Illusion Matter? An Experimental Approach

Self-Employment and Earnings among HighSkilled Immigrants in the United States

Industrial Relations and the Wage Differentials

between Skilled and Unskilled Blue-Collar

Workers within Establishments: An Empirical

Analysis with Data of Manufacturing Firms

Immigrant Adjustment in Israel: Literacy and

Fluency in Hebrew and Earnings

The Renumeration of British Academics

5

$7 / 00$

The Macroeconomics of Labor and Credit Market Imperfections

Sibling Rivalry in Educational Attainment:

The German Case

Space, Search and Efficiency

$8 / 00$

$8 / 00$

Discretionary Measures of Active Labor Market

Policy: The German Employment Promotion Reform in Perspective

Aggregate-Level Migration Studies as a Tool for 1 Forecasting Future Migration Streams

$8 / 00$

Intergenerational Influences on the Receipt of

3

$8 / 00$

Unemployment Insurance in Canada and Sweden

The Post-Unification German Labor Market

4

$8 / 00$ 
A. S. Kalwij

The Myth of Worksharing

A. Zaidi

Is Unemployment Really Scarring? Effects of

The Determination of Wages and the Gender 
220 W. A. Cornelius

E. A. Marcelli

221

C. Grund

222 W.P.M. Vijverberg

223 M. Rosholm

M. Svarer

J. Schwarze

L. Modesto

J. P. Thomas

P. A. Puhani

227

L. Locher
G. Brunello

S. Comi

C. Lucifora
R. Coimbra
T. Lloyd-Braga
L. Modesto

230

L. Modesto

231

G. Saint-Paul

E. Bardasi

M. Francesconi

C. Dustmann

C. M. Schmidt
The Changing Profile of Mexican Migrants to the

Wages as Risk Compensation in Germany

On the Identification of Relative Wage Rigidity Cross-Section Data and Empirical Evidence for Poland in Transition

Immigration from the Eastern Block and the former Soviet Union to Israel: Who is coming when?

The College Wage Gap in 10 European

\section{Fluctuations} and Earnings: An Empirical Study for Portugal 

1969-95 the 1990s

244 S. M. Fuess, Jr. M. Millea

Pay and Productivity in a Corporatist Economy: 
